\title{
Urdimento
}

Revista de Estudos em Artes Cênicas

E-ISSN: 2358.6958

\section{Cidade espaço inóspito: território do teatro de invasão}

André Carreira

\section{Para citar este artigo:}

CARREIRA, André. Cidade espaço inóspito: território do teatro de invasão. Urdimento, Florianópolis, v. 2, n. 38, ago./set. 2020.

DOI: http:/dx.doi.org/10.5965/14145731023820200024

Este artigo passou pelo Plagiarism Detection Software | iThenticate 
Cidade espaço inóspito: território do teatro de invasão

André Carreira ${ }^{1}$

\title{
Resumo
}

Este texto discute a cidade como espaço inóspito e violento, e sua abordagem pelas práticas de teatro de invasão. Esta modalidade teatral é analisada como estratégia dissidente com relação à lógica funcionalista da rua e como resistência à cultura da violência. O artigo também aborda o conflito como contexto dos processos de criação e habitação do espaço urbano pela experiência cênica.

Palavras-Chave: Teatro de rua. Violência. Espacialidades.

The city as an inhospitable space: territory of the invasion theatre

\begin{abstract}
This text discusses the city as an inhospitable and violent space, and how a theater of invasion may relate to this urban space, positing itself as a dissident strategy in relation to the street's functionalism and as a resistance to the culture of violence. This material also discusses the idea of conflict as a context for the processes of artistic creation and ocupation of the urban space realized by theatrical experiences.
\end{abstract}

Keywords: Street theater. Violence. Spatialaties.

1 Professor Doutor Titular da Universidade do Estado de Santa Catarina (UDESC), atuando no curso de mestrado e doutorado do Programa de Pós-Graduação em teatro (PPGT), bem como no curso de Licenciatura em Teatro (CEART/UDESC). Pesquisador PQ - CNPq. carreira@udesc.br 
O que é necessário é que o mundo seja um mundo do ser humano e não um mundo do mundo

(Hélio Oiticica, 1969)

Neste texto retomo os elementos centrais da minha pesquisa com relação às práticas cênicas na cidade, reafirmando o conceito da cidade como dramaturgia de um espaço inóspito. A partir disso exploro as noções de conflito e violência silenciosa para definir o ambiente do espaço da cidade, bem como para discutir o olhar cidadanista, tal como sugere o autor espanhol Manuel Delgado.

Considero a cidade como um espaço inóspito e violento, como âmbito do conflito, no qual intervêm as práticas de um teatro de invasão. A partir disso analiso as tensões dissidentes produzidas pelo teatro com relação ao funcionamento dos fluxos da cidade ${ }^{2}$, considerando os modos pelos quais este lugar de conflito ${ }^{3}$ é temporariamente transformado em espaço da ficção.

Assumo esta perspectiva porque interessa pensar sobre como as práticas artísticas invasivas dialogam com os procedimentos da cultura do cotidiano, com a situação de violência e com o controle institucional, transformando de modo efêmero, as formas de se habitar a cidade ${ }^{4}$. Meu interesse está relacionado com a

2 As tensões entre o projeto institucional, a planificação, o ordenamento e as necessidades e demandas individuais e coletivas fazem o espaço da cidade ser um espaço inóspito. Observe-se que o projeto urbano é controlado pela elite, por isso o ordenamento da cidade atende não somente as demandas funcionais, mas também resulta dos padrões culturais dos setores sociais hegemônicos. A maiorias das pessoas não influencia a gestão da cidade, portanto este não é o âmbito do acolhimento, mas sim o palco no qual a sociedade experimenta seus enfrentamentos políticos mais importantes. Isso é evidente pelo fato de que as grandes lutas políticas se resolvem nas ruas, no embate físico entre as forças da ordem e aquelas que querem alguma mudança. Na rua o conflito social e político se faz concreto. Por tudo isso, esse espaço inóspito é um espaço perigoso, é um espaço disputado. (Ver: Carreira, 2019).

3 Cabe aqui dizer que muitas pessoas que trabalham nas ruas tomam a ação do teatro como um gesto violento, porque afinal, o teatro está invadindo um espaço que supostamente estaria reservado para outros tipos de atividades. É verdade que a arte da cena não é sempre bem vinda às ruas. A visão romantizada, muito difundida entre grupos de teatro de rua, que "o artista tem que ir aonde o povo está", e que portanto, a rua seria o berço de nossa arte, não parece ter resposta semelhante da sociedade. Como arte marginal o teatro exercita sua capacidade resiliente para conquistar espaço social nas ruas e praças. O teatro de invasão parte do princípio de que esta disputa de espaços com a ordem institucional é legitima, ainda que implique em algum tipo de violência simbólica. O teatro de invasão coloca em discussão a cidade e suas representações sociais. Ao interferir no espaço e propondo novos arranjos espaciais este teatro está, pelo menos, questionando a hierarquia do rentável sobre o prazeroso, do produtivo sobre o ócio, das representações criadas pelo poder sobre a ficção das pessoas comuns.

4 Habitar a cidade no sentido de espaço praticado conforme propõe Michel de Certeau (1994). 
reflexão sobre como as tensões provocadas pelo ambiente de violência das cidades brasileiras dificultam, mas também convocam a interferência artística no espaço urbano.

A invasão do espaço será definida pela singularidade de cada lugar e pelos hábitos que predominam ali. Nos centros urbanos das grandes cidades se experimentará tensões diferentes de zonas periféricas. No entanto, em todos os espaços urbanos funcionarão lógicas de controle e ocupação que produzirão atritos como as formas cênicas que invadem tais espaços. Isso também implica afirmar que variarão as formas de se negociar as invasões e seu impacto sobre as pessoas que habitam os espaços. Por isso, os procedimentos de invasão teatral sempre deverão ser pensados considerando-se as particularidades dos ambientes nos quais tais invasões ocorrem. Como disse o antropólogo Nestor García Canclini, não existe uma cidade, mas sim múltiplas cidades que se sobrepõem, e estas cidades são definidas pelo território no qual se circula e pela sobreposição de usos de seus habitantes (Canclini, 1989). Não existe uma cidade unitária, pois esta se define por meio da percepção das pessoas em diálogo com a imagem institucional difundida massivamente. Portanto, como diz Canclini (2005, p. 107), “al llenarse de fantasías heterogéneas la urbe, programada para funcionar [...] se transborda y se multiplica en ficciones individuales y colectivas".

Considerando isso, a reflexão que apresento neste texto parte de um pensamento que toma a cidade como espaço definido pelas tensões que se dão entre as pessoas, a organização arquitetônica e o ordenamento legal. Como afirmou Walter Benjamin (1994), “as cidades são o plural de humanidade, uma acumulação e uma multiplicação de existências”5. A experiência de habitar a cidade é também construi-la através de nossa capacidade de imagina-la (Canclini, 2005). A partir disso, cabe analisar como os e as artistas que invadem a cidade a imaginam como espaço público, pois todas as pessoas que frequentam o espaço

Les villes sont le pluriel de l'humanité, un accumulation et une multiplication des existences. (Texto da Exposição La ville - Walter Benjamin Le passant, la trace, Centre Georges Pompidou, Galerie Nord, Paris 23 février - 23 mai 1994. Citado também por Jorge Mario Jauregui: http://www.jauregui.arq.br/favelas france articulations.html). (Tradução nossa) 
da cidade escrevem com seus corpos e suas ações o texto que é a própria cidade.

Há entre os e as criadoras de teatro na cidade muitas pessoas que partem da noção do espaço público como lugar de encontro, ao qual o teatro iria em busca do povo. No entanto, é importante questionar a idealização de tal encontro. Como diz Manuel Delgado (2011), pensamos que o espaço público suporia a ideia da liberdade formal e da igualdade de direitos. Mas, de fato exercemos nossos direitos neste espaço? O controle institucional e a violência limitam as possibilidades de tais encontros. Eles existem principalmente quando a intensidades dos acontecimentos rompem com o ordenamento e os comportamentos estabelecidos.

As dinâmicas e os conflitos do espaço publico fazem que essa seja "uma esfera da qual poderíamos nos apropriar, sem no entanto, podermos reclama-la como propriedade" (Delgado, 2011, p. 30). Este espaço pertenceria aos processos que nele se instalam, por isso a disputa com a ordem é uma das principais características que o definem.

Reconhecer a cidade como espaço inóspito é discutir esta idealização, coisa fundamental para tentarmos definir o lugar social de um teatro que invade a cidade. É preciso observar as contradições que o teatro enfrenta cada vez que se aproxima de iniciativas institucionais de ocupação de espaços da cidade idealizando-a como espaço do encontro.

Isso é particularmente importante quando refletimos sobre os processos de gentrificação que têm tomado forma nos centros empobrecidos de nossas cidades. E que afetam diretamente as práticas do teatro na cidade. As práticas teatrais que se oferecem em espaços de tensão entre as pessoas que habitam, caoticamente e perigosamente, lugares que a instituição governamental pretende recuperar para a cidade, estão obrigadas a questionar as implicações políticas de suas intervenções neste processos. Por isso, a discussão sobre o conceito de espaço público que propõe Manuel Delgado reveste-se de importância, uma vez que este conceito: 
No se limita a expresar una mera voluntad descriptiva, hoy día transmite una fuerte connotación política. Como concepto político, se supone que significa una esfera de coexistencia pacífica y armoniosa de la parte heterogénea de la sociedad, evidencia de que lo que nos permite convertirnos en sociedad es que estamos de acuerdo en un conjunto de postulados programáticos dentro de los cuales surgen las diferencias, que son superadas, sin ser olvidadas o totalmente negadas, si no se deja de lado, en esta otra etapa a lo que llamaríamos privado. Este espacio público se identifica, por lo tanto y teóricamente, como el alcance y el libre acuerdo entre los seres autónomos y emancipados que viven, mientras realizan en él, una experiencia masiva de desafiliación. (Delgado, 2010, p. 114).

Então o espaço público não poderia ser pensado como espaço de encontro entre pessoas livres e iguais, porque isso é absolutamente contraditório com a realidade do mundo no qual vivemos. Se usamos a ideia do espaço público não seria para reafirmar idealmente a noção de esfera pública, de modo a reivindicar um humanismo ou cidadanismo das ruas e praças. Podemos pensar o espaço público reconhecendo-o como espaço de tensão e contradição, como arena em que forças diversas operam tratando de construir possibilidades ${ }^{6}$.

A ideologia cidadanista criticada por Miguel Delgado trataria de resgatar os restos do esquerdismo de classe média, "uma ideologia social democrata preocupada com a necessidade de harmonizar espaço público e capitalismo, com o objetivo de alcançar a paz social e a estabilidade que permita preservar o modelo de exploração" (Delgado, 2010, p. 115). Diferentemente dos discursos que reivindicam o cidadanismo o pensamento que fala de invasão reconhece o inevitável dos conflitos e o pouco hospitaleira que a rua é frente às rupturas de usos ${ }^{7}$ que propõe

${ }^{6}$ Hoy, de hecho, las ideas de ciudadanía y, por extensión, del espacio público serían ejemplos de ideas dominantes, en un doble sentido, de ideas de quienes dominan y de ideas que están diseñadas para dominar, porque son ejes que justifican y legitiman la gestión que se convertiría en un consenso coercitivo o una restricción en cierta medida consensuada con los mismos coaccionados. Estamos ante un ingrediente fundamental de lo que en nuestros días, es lo que Foucault llamó 'la modalidad pastoral del poder', refiriéndonos al pensamiento político griego, tan inspirador del modelo 'ágora' en el cual dice estar inspirado el discurso del espacio público: era un poder que se ejercía sobre un bando de individuos diferenciados y diferentes a cargo de un jefe que debía calmar las hostilidades dentro de la ciudad y hacer que prevaleciera sobre el conflicto. (Ver: Foucault, 1991, p. 101-102) (26).

Compreender a dinâmica da cidade a partir da ideia de repertório de usos (Da Matta, 1997, p. 30-31), permite que tenhamos uma imagem mais clara das combinações entre o espaço arquitetônico, os conflitos e a construção do imaginário dos usuários da cidade. Este repertório apresenta muitas variações de acordo com o momento do dia, mas também se altera de acordo com o calendário, no entanto, por se tratar de uma construção coletiva está sempre interferido pelos conflitos. É o repertório de usos que vai dar forma ao 
o teatro.

A idealização do espaço público pode ser articulada como estratégia para desestimular usos não apropriados das ruas, pois em nome da convivência cidadã também se pode exercer controle do espaço da cidade (Delgado, 2010). Não é difícil ver como isso pode ser facilmente apropriado pelos discursos de limpeza e ordem que servem de justificativa para regulamentar o uso do espaço da cidade. Começa-se pelo argumento de controle da delinquência, passa-se pelos/as semteto, chega-se aos e às artistas, e tem-se na mira as manifestações políticas críticas ao poder. Esta lógica pode soar simplista, mas não é difícil observar como estas formas de controle se replicam nas cidades brasileiras nos últimos dez anos.

A complexidade deste fenômeno no entanto, convoca a um olhar mais detalhado porque é verdade que habitar o espaço da cidade implica inevitavelmente em alguma forma de convivência que ofereça às pessoas a oportunidade de estar na cidade. O teatro que invade a cidade opera exatamente nesse território provocando reflexões sobre modos de ocupação e usos do espaço da cidade que contemplem a diversidade, ou pelo menos questione os usos estabelecidos. Este teatro pode ser uma força poética desorganizadora deste espaço, e desta forma produzir fissuras ou dissidências frente à lógica violenta que está implícita nas práticas de controle.

Trabalhar com a ideia de um teatro acontecimento, e destacar que sua realização é um ato de re-escritura da cidade, implica reconhecer que os e as artistas da cena serão autoras que interferem nos fluxos e no imaginário urbano. Este teatro discute a violência das ruas, não apenas do ponto de vista conceitual, senão que, como prática dissidente se afirma reivindicando outros modos de se estar na cidade.

Penso o conceito de teatro de invasão considerando a ideia da cidade como dramaturgia (Carreira, 2019). O principal elemento textual do teatro que invade o espaço urbano é a própria cidade, por isso atores e atrizes que ocupam este espaço o leem como uma dramaturgia que também os inclui. A duplicidade de

fluxo urbano. (Lynch, 2006). 
fazer e ver-se ao mesmo tempo impede que esta modalidade teatral possa ter como seu eixo a busca da cidade espaço cenográfico onde melhor representar uma dramaturgia específica.

Este é um fenômeno inerente ao estar na rua, sempre observamos a cidade e somos agentes de sua construção. Então o ambiente da rua impede que se possa estar apenas desenvolvendo um plano do trabalho da ficção, consequentemente, lê-se a cidade e, simultaneamente, se faz parte deste texto.

As e os artistas da cena podem não ter consciência deste fenômeno, mas ele decorre das próprias regras de funcionamento espacial. No entanto, quando se tem consciência da duplicidade pode-se aprofundar a experiência criativa na cidade e assim, descobre-se operações mais complexas do habitar o espaço urbano. Deste modo, a duplicidade a que me refiro é um elemento chave das práticas invasivas porque permite trabalhar com diferentes dimensões da cena urbana.

O teatro de invasão aciona ficcionalmente como uma forma alterna de se habitar a rua. Invadir é, nesse caso, tomar o espaço no contexto de uma disputa pela construção de imaginários urbanos, usando a ficção como ferramenta de corta o cotidiano ${ }^{8}$. Fazer parte dessa escritura/construção, implica compreender as dinâmicas do espaço urbano, e como se dá esta escritura que é também uma fabricação da própria cidade. Estes complexos processos exigem pensar a presença do teatro na cidade como algo além da simples representação cênica.

\section{Espaço inóspito}

A cidade é um espaço contraditório que pode ser o lugar da experiência livre ou do controle, do medo e da ameaça. No Brasil este é cada vez mais um espaço pouco amigável, onde cidadãs e cidadãos se enfrentam a diferentes formas de violência, e vivem em estado de alerta.

8 Ver André Carreira em entrevista ao Jornal Caixa de Ponto, 2015. 
É importante lembrar que as intensidades dos conflitos que caracterizam na atualidade nossas ruas exigem um olhar particular para os fenômenos que se dão no nosso contexto urbano. Inúmeras pesquisas realizadas pelas universidades brasileiras dão conta do incremento da violência urbana no país a partir do final da década de 1970. Como diz a pesquisadora Marcia Regina da Costa (1999, p. s/p.):

\begin{abstract}
$\mathrm{Na}$ década de 90, o sentimento das pessoas que vivem nas cidades brasileiras é de medo e perplexidade diante da brutalidade de muitos crimes, assaltos e homicídios. Mas, o grande espanto é com a aparente frieza e ausência de limites de muitos dos criminosos que praticam tais atos. Esses homicídios desenrolam-se dramaticamente em nosso cotidiano. [...]. Esta selvageria e crueldade não ocorrem apenas nos assaltos. Em Brasília, um fato recente chocou o país. Jovens de classe média alta atearam fogo ao corpo de um índio que dormia nas ruas da cidade. E, na tentativa de se defenderem perante a polícia, argumentaram que não sabiam que a vítima era um índio, que pensaram que era "apenas um mendigo" e que tinham jogado gasolina e posto fogo às suas vestes "por brincadeira" [...]. Esses relatos somam-se ao daqueles que vivem nos bairros populares das cidades brasileiras. O cotidiano dos moradores de bairros da periferia de São Paulo transformou-se radicalmente, no início dos anos 80, com a violência.
\end{abstract}

Esta breve citação não soará para leitoras e leitores do Brasil nada surpreendente, dado que a percepção geral que temos de nossas cidades, devese em muito às imagens de violência que se repetem diariamente nas telas da televisão e nas páginas dos jornais, bem como nas redes sociais. A isso devemos somar de modo decisivo a sistemática violência policial que é um fator preponderante para a mais absoluta sensação de insegurança que invade as cidades brasileiras quase sem distinção de tamanho e localização geográfica. Também é preciso fazer referência à violência dos discursos de ódio que, a partir do processo de derrubada do governo de Dilma Rousself, tem se manifestado de modo mais presente nas ruas. Movimentos reacionários têm se apresentado nos espaços públicos como uma ameaça aos discursos divergente, incorporando desse modo mais um fator violento para as práticas artísticas nas ruas ${ }^{\text {. }}$

9 Isso tem sido particularmente experimentado por artistas performativos que foram alvo de ataques de grupos conservadores como o auxílio imediato das forças policiais. Um exemplo foi o artista Maikon K com sua obra O DNA de Dan, reprimido pela polícia militar do D.F. quando se apresentava em turnê pelo projeto 
Além desta violência imediata, ainda devemos considerar a violência simbólica imposta diariamente pela gestão dos estados municipais e estaduais, que fazem de nossos núcleos urbanos territórios de discriminação social e da exploração descontrolada por parte da iniciativa privada. Esta violência rouba dos e das cidadãs os espaços que thes pertencem, para cedê-los a exploração de interesses empresariais, não só segmentando o convívio, como normatizando-o sem considerar as necessidades das pessoas.

A prática violenta das instituições pode ser relacionada com a noção de violência sistêmica tal qual sugeriu Slavoj Zizek. Uma violência invisível e anônima, mas concreta, e que está instalada na base da estrutura social. Essa violência se manifesta através de imperativos coercitivos sobre a maioria da cidadania (Zizek, 2009). Interessa muito explorar as formas como os modos silenciosos de violência se dissimulam como adversidades, e persistem como um infortúnio. Isto configura na realidade, uma sistemática prática violenta contra a vida e o prazer. Muitas destas violências invisíveis podem ser vinculadas às práticas disciplinantes identificadas por Michel Foucault. Como diz Edgar Straehle estas violências podem ser percebidas:

No como actos propia o plenamente violentos sino como adversidades desagradables o desafortunadas, en absoluto deseables pero tampoco escandalosas, sino más bien inevitables hasta cierto punto y nimbadas con un aura de normalidad. Que este tipo de violencias se diferencien en gran medida de la física y sean más etéreas o sutiles, que se enmascaren a menudo bajo otros semblantes, ha llevado a que se haya llegado a hablar de ellas como violencias dulces y a fin de cuentas como no violencias, lo que no hace más que favorecer su multiplicación y recrudecimiento, convirtiéndose de este modo en una fuente nada desdeñable de conflictos sociales. Uno de los principales problemas a la hora de enfrentarse con estas violencias reside en que han sido interiorizadas efectivamente como justificables, lo que ha facilitado la permisibilidad o asimismo una suerte de consentimiento, sea tácito o explícito, por parte de lo que la sufren. (Straehle, 2014, p. 429).

Para Straehle este tipo de violência se caracteriza por sua eficácia porque é uma violência difícil de ser denunciada, e é apresentada como necessária ao modo de convivência, e assim pode encontrar mais facilmente argumentos jurídicos a 
seu favor. Este quadro faz que estas violências se propaguem assumindo a característica da violência burocrática que se espraia no modo de vida, incorporando-se ao cotidiano como "encarnações democráticas da violência" (Straehle, 2014, p. 34). A invisibilidade de tal violência não supõe inexistência de comportamentos de resistência. Isso pode ser percebido na persistência de formas de ocupação dos espaços que são dissidentes com relação ao normatizado.

Este é um componente fundamental para pensar a cidade como um território inóspito que se define pela combinação das ameaças de violência física com esta violência não violenta. A tensa trama do espaço urbano é resultado da sobreposição de camadas de violência e das ações da cidadania que trata de resistir aos atos violentos.

Em diferentes zonas das cidades brasileiras - tanto em áreas centrais pauperizadas como em áreas periféricas - as instituições utilizam a eficácia da violência silenciosa em combinação com a violência explícita, como forma de controlar e normatizar o espaço coletivo.

Considerar este espaço como inóspito não implica em pensar que o conflito nasce de um comportamento naturalmente competitivo do ser humano em relação ao território. O conflito decorre da permanente tensão entre os indivíduos e a ordem institucional nas suas mais diferentes formas, e principalmente do controle social. Um exemplo disso é a contradição entre o pensamento funcional e as práticas lúdicas, entres as quais podemos incluir o teatro. A cidade, por meio de diversos modos de controle, prioriza as atividades que respondem a uma funcionalidade produtiva claramente estabelecida, ou trata de disciplinar todas as atividades buscando inseri-las em seus sistemas de produtividade.

As pessoas protagonizam - consciente e inconscientemente -, várias ações que se enfrentam com aquilo que oprime, agride ou controla seu livre fruir do espaço da cidade. Esta resistência pode ser percebida também em ações artísticas articuladas como práticas de ocupação de território. Como exemplos, entre muitos, se pode citar experiências performáticas, apropriações de paredes por 
pichações, pinturas de painéis, instalações de esculturas não oficiais ou efêmeras, e inclusive práticas de flash mobse rolezinhos. Mas, além disso, também podemos constatar, por exemplo, que a reunião de adictos ao crack em zonas que terminam conhecidas depreciativamente como cracolândias, representa um modo dissidente em relação à lógica de controle estatal que trata, ainda que de modo ineficaz, de disciplinar de forma definitiva a coletividade de usuários e pequenos traficantes.

A cidade brasileira é um território inóspito devido ao alto grau de violência cotidiana, à ameaça que nos oferecem as forças policiais, e ao profundo desprezo do estado pela gestão do aparelho urbano. Tudo isso obriga as e os pedestres elemento não hegemônico da cidade - a vencer inúmeros obstáculos para poder circular diariamente pela cidade, e fazer isso sabendo que corre riscos iminentes ${ }^{10}$.

A avalanche de informações e espetacularização que várias empresas de comunicação e várias correntes políticas e religiosas protagonizam todos os dias por meio da televisão e do rádio, magnifica a violência e define um campo de classe para explica-la, assim a isola de um tecido social marcado pelas extremas diferenças de poder aquisitivo. Isso cumpre um papel decisivo na configuração daquilo que se pode chamar impacto mediático da violência, cujo resultado é um grande espetáculo que combina uma profunda sensação de desproteção com a insistência no impulso de revanche social. Este é um elemento fundamental na configuração do imaginário da cidade brasileira, o que reafirma a angústia e incerteza como as sensações das quais é impossível escapar cada vez que nos colocamos a refletir sobre o degradado espaço público de nossas cidades. De um modo geral, este é o contexto das nossas ruas, particularmente aquelas das periferias das cidades, bem como dos deteriorados centros urbanos nos períodos

10 Como diz Márcia Regina da Costa (1999, p. s/p): “As maiores vítimas das violências e homicídios não são os ricos, mas os pobres e excluídos. Os privilegiados economicamente sempre podem contratar seguranças particulares, encerrar-se em condomínios de luxo protegidos ou transferir a família para Miami, como vem acontecendo no Brasil, em decorrência da onda de sequestros. Já os pobres não possuem meios e, em muitas situações, nem sequer podem contar com o poder público para se defender das violências, da polícia, dos traficantes ou de outros tipos de gangues. Comprovando esta realidade, algumas pesquisas revelam o caráter altamente segregado de centros urbanos, como nos casos de São Paulo e Los Angeles, onde os ricos encerram-se em espaços privados, verdadeiros enclaves fortificados para o lazer, trabalho, moradia e outras atividades. E isso ocorre mesmo que o resultado seja mais segregação urbana e violência". 
noturnos.

Devemos considerar, como propõe Robert Castel (2008, p. 13-14) que:

La sensación de inseguridad no es exactamente proporcional a los peligros reales que amenazan a una población. Es más bien el efecto de un desfase entre una expectativa socialmente construida de protecciones y las capacidades efectivas de una sociedad dada para ponerlas en funcionamiento. La inseguridad, en suma, es en buena medida el reverso de la medalla de una sociedad de seguridad.

Mesmo assim, é preciso compreender que a lógica do medo é produtora de regras espaciais e da normatização da convivência ${ }^{11}$. O teatro na cidade se encontra exatamente nesse ponto nevrálgico porque interfere nas regras espaciais, tanto ordenadas pela instituição como por aquelas geradas pelos usuários do espaço. ${ }^{12}$

As condições de pauperização de zonas das cidades do Brasil que se transformaram em territórios de medo, e a inflação a que se refere Castel servem de justificativa para discursos institucionais que argumentam em favor do resgate do espaço público. Isso repercute principalmente em projetos de limpeza de áreas da cidade através de processos de gentrificação, que são instrumento da reciclagem e capitalização dos espaços que, via-de-regra, terminam em turistização dessas áreas.

Durante estas ações predominam medidas higiênicas que buscam tornar invisíveis as contradições sociais deslocando para outras zonas da cidade populações mais pobres. Exemplos recentes disso puderam ser observados na preparação do país para o Campeonato Mundial de Futebol (2014) e para os Jogos Olímpicos (2016), quando os governos municipais e estaduais de diferentes partes do pais, com a conivência necessária do governo federal, realizaram várias ações arbitrárias de recondicionamento de bairros para criar "novos" espaços de

11 Para Castel "a inflação da preocupação pela segurança dissolve finalmente a possibilidade de se estar protegido, e instala o medo no centro da existência social”. [La inflación de la preocupación por seguridad disuelve finalmente la posibilidad de se estar protegido, e instala el miedo en el centro de la existencia social] (2008, p. 80). Cabe dizer que nas últimas duas décadas o crime organizado com o tráfico e as milícias tem uma presencia fundamental do mapa da violência urbana no país.

12 Castel (2008, p. 114) ainda diz que: "Se ha enfatizado que las desviaciones recientes de la reflexión sobre el riesgo alimentaban una mitología de la seguridad, o más bien de la inseguridad absoluta, que culmina en última instancia en una denegación de la vida”. 
convivência ${ }^{13}$.

Porque sabemos que nossas ruas são espaços inóspitos, construímos táticas de circulação e convivência com o fim de sobreviver a cada dia, e estamos habituadas a tomar precauções ao sair de casa. Ao entender isso como algo natural, vamos perdendo a capacidade de nos indignar frente o inóspito de nossas cidades, e inclusive aceitamos a shoppingsização dos espaços com certo alívio.

\section{O conflito}

Além da violência mencionada, existem outros níveis de tensões que fazem das ruas espaços inóspitos que o teatro enfrenta. Como espaços de circulação e convívio momentâneo, as ruas estão constituídas por uma grande variedade de forças e interesses diversos. Isso favorece contradições que produzem tensões e negociações relativas aos diversos processos de ocupação e controle da rua.

A perspectiva da sociologia funcionalista que tem como base o pensamento de Durkheim, considera que a sociedade se organiza na cidade a partir de adaptações e da conquista de metas, o que levaria, finalmente, a processos de integração coletiva. No entanto, para compreender as dinâmicas complexas da convivência no espaço da cidade, interessa considerar o conflito como um mecanismo permanente que não caminha em direção a uma estabilidade harmoniosa do coletivo.

Tomar o conflito como elemento intrínseco da cidade pode ajudar a entender as camadas mais dinâmicas das operações que definem o espaço urbano. Do conflito provêm muitos elementos culturais e práticas relativas às formas de estar/usar os espaços da cidade. É instigante pensar, como propõe Pedro Luis Lorenzo Cardaso, a partir das teorias vulcânicas do conflito. Estas teorias argumentam que o conflito resulta da escalada de tensões que pode ter origem em processos políticos, que são decorrentes de desacordos socioeconômicos, ou

${ }^{13}$ Isso pode ser observado no caso do reordenamento da zona portuária do Rio de Janeiro onde se organizou um espaço de convivência destinado principalmente a ser mais uma atração turística, sem se considerar a possibilidade de diálogo com os e as habitantes originais do bairro. 
são consequência de fatores psicológicos (Cardaso, 2001). O conflito se daria por meio de espasmos que se manifestam quando as circunstâncias fazem que os atores sociais cheguem a níveis impossíveis de se evitar a crise, e se cruzam umbrais de tolerância' ${ }^{14}$. Como diz Cardaso (2001, p. 245):

É importante o componente psicológico desta interpretação do conflito [...] com parâmetros conceituais similares os psicólogos estudam das desavenças conjugais ou familiares até as revoluções. O exemplo mais acabado de aplicação destas teorias pode ser encontrado no sociólogo estadunidense J. Daves e seus estudos sobre rebeliões e revoluções [...]. Segundo este autor, as expectativas podem ser de dois tipos, as econômicas e as de poder e status, mas se ambas confluem quando se produzem as grandes sublevações.

Nos espaços da cidade que estão marcados por diferentes padrões de convivência, os conflitos são produzidos tanto por aspectos sociais de base socioeconômica, como por fatores relativos aos hábitos de uso do espaço, e até mesmo por tensões culturais e ideológicas. A sobreposição de fatores nos ajudaria entender melhor este lugar - a rua e suas dinâmicas ${ }^{15}$ - como espaço conflitivo.

O plano de conflito mais imediato se define pelas tensões entre o uso funcional do circuito de consumo, o ordenamento de controle e o estar na cidade como prática social ou cultural. As iniciativas do capital lutam por dominar os espaços, e construir regras que favoreçam o consumo por sobre todas as outras práticas da cultura, e a maioria das iniciativas governamentais colaboram com este enfoque a partir do argumento da economia.

Por outro lado, existem inúmeras iniciativas coletivas ou individuais que buscam criar espaços de convivência, ou reivindicam a cidade como lugar relacional16. O teatro, via-de-regra, se inscreve nesta segunda vertente, e isso já explicita um ponto de conflito, dado que nossas práticas no espaço da cidade

14 Ver Durkheim, 2000.

15 As ruas se transformam devido aos ciclos de ajustes de funções e usos que se adaptam às demandas que se impõem diariamente.

16 A ideia de espaço relacional implica compreender o território não apenas a partir de sua dimensão física, mas sobre tudo considerando as dinâmicas que o definem temporalmente. 
também contribuem para fazer visível as tensões que subjazem entre os mais diversos usos deste espaço. Além disso poderíamos enfatizar a inutilidade do teatro como fator dissidente.

A antropologia urbana vê as práticas artísticas como uma referência que favorece a observação de operações e contradições do espaço da cidade. Neste sentido é interessante ver, como dizem Costa e Lopes (2018, p. 1), que "as intervenções artísticas na esfera pública podem ser uma boa forma de compreender os múltiplos estratos de uso e camadas de segregação que se encontram nos complexos organismos que são as cidades”.

Considerando o contexto de violência explícita ou silenciosa, os conflitos e a tensão dos diferentes modos de apropriação e uso do espaço da cidade, podemos formular uma noção de espaço de cena que resulta de variadas sobreposições de elementos. A sobreposição explicita principalmente as diversas formas de compreender e fabricar o espaço da cidade. Frente a isso interessa pensar as ações teatrais como um destes fatores, que sem convite, invadem este espaço com o desejo de produzir transformações nas regras culturais do status quo, e a seu modo, se propõem a construir a cidade. Partindo do lugar subalterno e deslocado que o teatro ocupa no quadro de valores culturais, esta arte busca a partir das práticas baseadas na proximidade e na quebra de regras de comportamento, criar formas efêmeras de habitar o inóspito espaço urbano.

A dissidência com relação à cultura da violência mostra um aspecto que permeia as experiências do teatro na cidade, porque este teatro se formula principalmente como resposta aos processos de privatização do espaço público e da regulamentação do convívio. Sua ação que introduz o lúdico, a ficção neste âmbito, o que o propulsiona a se opor com os mascaramentos do quadro de violência das ruas. Propor um jogo teatral que corta o cotidiano e questiona os regramentos do espaço, faz explícita a face política de um teatro que se mostra no enfrentamento à lógica institucional do controle, e na reivindicação da cidade como lugar das pessoas. 


\section{Espaço e ambiente da experiência corporal}

A rua, espaço oposto ao espaço da intimidade, é âmbito do impessoal e do anonimato. Este espaço fora, como diz Foucault (1967, 2/p), nos levaria para fora de nós mesmos porque ali "se desenvolve precisamente a erosão de nossa vida, de nosso tempo e de nossa história, este [é um] espaço que nos corrói e nos fissura". ${ }^{17}$ É um espaço liminar, e como dizem Furlan e Silva (2019, s/p), a partir de Foucault: "confrontar um limite significa explorar um lado de fora de uma experiência possível; por isso, a experiência-limite pode ser compreendida como uma experiência do fora".

A condição de insegurança das ruas implica em um fora que impõe deslocamentos, por isso a rua, é simultaneamente uma ameaça e um lugar de possibilidades, que nos confronta com nossos limites. Ela oferece e demanda. Mas, ainda que predominem a impessoalidade e o anonimato, eventualmente isto é cruzado por experiências de intimidade, dependendo das intensidades das experiências corporais que se realizam neste espaço público.

O ambiente condiciona e é condicionado pela experiência dos corpos, porque estes são fatores na construção ambiental, eles são ambiente. Como afirma Richard Schechner, o ambiente começa no corpo (1994), por isso é imprescindível considerar as relações entre as pessoas e os lugares habitados. Para o geógrafo Yi-Fu Thuan (2008, p. 41): "Toda pessoa é o centro de seu mundo, e o ambiente espacial é diferenciado de acordo com seu esquema corporal. O modo como ela se move e gira, cria as regiões de frente e de costas, esquerda e direita ao seu redor".

Considerando estes pontos de vista pode-se dizer que usamos o espaço ajustando nossa percepção das dinâmicas do ambiente. Assim, habitamos as ruas em um processo de constante transformação, o que implica tanto na modificação

17 En el que se desarrolla precisamente la erosión de nuestra vida, de nuestro tiempo y de nuestra historia, este espacio que nos carcome y nos agrieta es en sí mismo también un espacio heterogéneo. Dicho de otra manera, no vivimos en una especie de vacío, en el interior del cual podrían situarse individuos y cosas. No vivimos en un vacío diversamente tornasolado, vivimos en un conjunto de relaciones que definen emplazamientos irreductibles los unos a los otros. (Tradução nossa) 
do que vemos como do que somos e como articulamos este ambiente. Esse é um ponto de partida para pensarmos a rua como espaço da cena, pois a invasão poética realizada pelo teatro implica em uma transformação - efêmera, mas significativa - das pessoas que fazem e das que assistem a prática artística. Esse é o ponto chave de sua intervenção ambiental.

O ambiente é uma articulação de elementos físicos, sensoriais e afetivos, e é fabricado através da ação das pessoas e das instituições em relação com as condições físicas do espaço. Por isso, o ambiente é resultado das dinâmicas coletivas e individuais, porque é onde se vivem as experiências e se produzem os afetos.

O teatro é uma força ambiental que opera cada vez que ocupa os espaços da cidade porque se manifesta como um vetor dos dispositivos espaciais, e ainda que seja de modo efêmero, interfere nos sentidos do espaço. Consequentemente, a criação de um teatro de invasão deve considerar central a sua capacidade de redefinir momentaneamente o ambiente urbano. Por isso, este teatro tem como prioridade a criação de dispositivos/mundos que afetem de múltiplas formas, os processos do habitar a cidade (Carreira, 2019).

Uma possibilidade para pensar sobre uma cena invasiva é ir além da nossa tradição teatral e fazer referência às práticas criativas de Hélio Oiticica, artista que buscava o ambiental como condição de seus objetos penetráveis e instalações ${ }^{18}$. Como diz Wisnik, Oiticica que tinha uma "grande resistência a aderir a uma dimensão mais edificante de espaço público" nos anos 70 (2017, s/p), reconhecia o fluxo aleatório das pessoas e questionava a cultura do patrimônio como coração da arte no espaço público. Para este pesquisador o programa ambiental de Oiticica (1966) se baseava em negar a representação e a contemplação, para buscar a participação dinâmica do espectador.

Oiticica tinha um olhar dissidente com relação ao uso do espaço público e sua ideia de participação dos e das espectadoras na experiência artística supunha

8 Como diz Guilherme Wisnik Teixeira (2017, S/p): Oiticica propõe que os trabalhos de arte realmente vitais sejam colocados em terrenos baldios da cidade, como "uma obra perdida, solta displicentemente, para ser "achada" pelos passantes, ficantes e descuidistas" Concretamente, a materialização dessa proposta é o Bólide Lata-fogo. 
a apropriação de elementos da realidade para sua incorporação nas obras no âmbito público. Este é um antecedente que ecoa nas realizações de um teatro que ocupa o espaço urbano, ainda quando se pode notar que no meio teatral pouco se faz referência ao trabalho inovador desenvolvido por Oiticica nos anos 1960 e 1970.

A ideia de que os e as transeuntes sejam responsáveis pela inserção do real na obra aponta para uma ruptura com relação ao papel do discurso. Oiticica estava completamente imbuído da necessidade da experiência corporal do espectador com o objeto artístico, porque considerava isso um acontecimento ambiental que se projetaria para muito além da contemplação da obra. Pode-se observar que seus objetos penetráveis supunham a fruição corporal do espectador para sua plena realização. Esta perspectiva da participação no ambiente permite voltar a refletir sobre um teatro que considera a cidade como espaço da cena a partir da possibilidade de que sua intervenção artística modifique o uso do espaço, estimulando ações que transformem o ambiente a partir da ruptura dos comportamentos cotidianos. Haveria potencialmente uma mutua interferência do público (força do cotidiano) e da performance (força da fiç̧ão) na construção do acontecimento ambiental.

O teatro tem uma temporalidade que é distinta da temporalidade funcional que impera na cidade, e isso produz tensões ambientais, e inevitavelmente implica em potenciais conflitos com o funcionamento ordenado do tempo da circulação e do consumo. Os ritmos marcados pela violência e o medo, pelo conflito, e pelo controle, entram em contradição com os usos poéticos do espaço que o teatro demanda.

A perspectiva de uma cena ambiental também coloca em discussão as linhas da tradição teatral que entendem as relações entre cena e espaço a partir da interpretação do texto dramático, que supõem sempre a predominância dos elementos cognitivos da encenação e a função cenográfica do espaço. Ao se trabalhar a partir de uma abordagem ambiental se estará dialogando com o acontecimento cênico e social, com a multiplicidade de modos de interação com a cidade e seus conflitos. 
Partir da ideia da experiência cênica como uma experiência no ambiente é possível compreender que o plano das sensações e percepções das pessoas que intervêm no acontecimento da cena passa a ser, senão prioritário, pelo menos tão importante como as ideias da dramaturgia. Isso pode ser relacionado com o tipo de participação a que se referia Oiticica quando formulou sua ideia do objeto penetrável ou de objeto envoltório. Aquilo que afeta a pessoa que penetra ou é envolvida pelo objeto, é o que definirá os significados do objeto.

Uma cena que percebe a cidade como um espaço penetrável e espaço envoltório, dialogará com o plano dos afetos e da afetação, porque este teatro não estará regido apenas a partir do elemento cognitivo do texto, nem terá como foco que o público contemple sua apresentação.

O ambiente composto principalmente pelas pessoas, suas dinâmicas e suas percepções, estabelecerá as condições para que a experiência sensorial de penetrar o espaço e ser envolvido por ele, seja a base da relação com a ficção, e impulso para o jogo. O centro das experiências cênicas que invadem a cidade deve ser, portanto, o diálogo entre atores, atrizes e o público, pois este é o elemento chave da experiência criativa no aqui e agora do fazer a cidade.

A faceta ilustrativa do espaço arquitetônico como suporte da encenação, é algo secundário se pretendemos compreender o teatro de invasão. Ainda que possam existir alinhamentos entre determinado espaço e uma montagem, o foco de um teatro na cidade, é incorporar tal espaço enquanto experiência, na própria realização-recepção do espetáculo. Isso pode ser alcançado quando o público decide participar do jogo da cena, e a encenação não enfatiza sua condição de representação para uma audiência, ou seja, quando o jogo funciona, ainda que de forma momentânea, como uma inversão do mundo. O jogo pode propiciar comportamentos liminares - visitas a territórios proibidos -, colocando corpos e mentes em situações nas quais o controle social e a norma podem ser questionados ou violados.

A ruptura do cotidiano pela fiç̧ão e pelo jogo reforça potencializa a face lúdica latente deste espaço, apesar de que ali a vida está normatizada e 
controlada, privilegiando os processos relacionados com a vida econômica. São poucos os momentos nos quais a energia do estar na rua está dedicada ao jogo livre, e via-de-regra quando isso ocorre o establishment e as forças empresariais descobrem formas de produzir benefícios políticos e financeiros ${ }^{19}$.

A conquista de espaços de jogo, nos quais as e os simples transeuntes possam se transformar em sujeitos do jogar, e assim desfrutar do lúdico compartilhado com estranhos/as, resultará das lutas capilares que se dão entre a instituição e as práticas culturais entre as quais se inscreve o teatro de invasão.

A inversão das regras do mundo, condição básica do jogo segundo o antropólogo Jean Duvignaud (1980), é o objetivo fundamental de uma ação cênica que interfere no espaço público, porque é justamente a hipótese da inversão que colocaria em discussão o predomínio da lógica funcional e produtivista da cidade, e portanto, da naturalização do estado de violência.

O disciplinamento das ruas articulado sob o discurso da ordem cidadã constitui prática comum na atualidade. Frente a isso a experiência performativa do teatro na cidade se oferece como instância de ruptura com tal lógica, e trata de instalar experiências distintas do habitar. Explorar as mais variadas possibilidades de jogo com as estruturas do cotidiano que nos propõe o teatro de invasão, é o desafio que deve enfrentar quem experimenta habitar a rua com o teatro. Não se deve esquecer, entretanto, que estas práticas se dão como dissidência de uma lógica hegemônica, e têm um caráter efêmero e ao mesmo tempo bastante marginal.

À condição periférica de tal prática artística não the resta importância como projeto alternativo à lógica do controle da cidade, bem como à lógica da violência. O teatro se articula como uma fala que resiste a aceitar absolutamente um projeto de cidade que alija as pessoas do seu centro vital.

A representação da peça coerentemente encenada para a compreensão do

19 Podemos observar isso nas incansáveis gestões para que se exerça controle institucional sobre o carnaval e outras manifestações de rua. Ao mesmo tempo vemos que diversas organizações culturais buscam preservar a potência criadora das iniciativas não institucionais, reforçando a presença do conflito com relação ao imaginário da rua. 
público, e sustentada em um enquadramento cenográfico da arquitetura, não amplia o diálogo com a cidade porque se limita a uma oferta do teatro como espetáculo, no qual os e as transeuntes terão pouca ou nenhuma oportunidade de colocarem-se em tensão com a lógica da cidade funcional. Ao não propor a discussão da própria cidade como lugar social e político, e não questionar as regras do espaço a partir da linguagem da cena, o teatro estaria negando seu papel de construtor da cidade.

O jogo no ambiente, discute as formas de habitar a cidade, porque é um jogo social que se formula a partir da articulação entre planos da ficção e planos da realidade. A perfuração do cotidiano por ações cênicas só ocorre efetivamente quando se põe em risco a continuidade do fluxo regular das pessoas que transitam pelas ruas. Este jogo pode explorar novas formas de se estar na rua, pois assim estará abrindo possibilidades de que se discuta o ordenamento funcional do espaço.

O teatro que invade a cidade deve ser uma instância de experiência para todas as pessoas que circulam pelo espaço público, e como arte viva deve estimular que os e as transeuntes sejam elementos cruciais na construção do acontecimento teatral. Se estamos na rua ou na praça aonde acontece uma prática teatral, podemos ser coautoras/es da mesma, ainda que apenas nos movimentemos pelo espaço. Aceitando ou resistindo ao jogo da cena, estaremos participando porque nossas presenças farão parte do contexto ambiental. Não é necessária uma participação consciente e instrumentalizada pela montagem para que sejamos partícipes. Estaremos em cena apenas por estarmos no espaço da rua atuando em simultaneidade com a apresentação/acontecimento cênico. Isso ocorrerá sempre e quando outras pessoas nos vejam e possam criar planos de olhar que sobreponham os planos da ficção e do cotidiano. A cena da cidade é transparente e porosa (Carreira, 2019), e isso permite que ela seja atravessada pelo olhar de pessoas que apenas passam rapidamente pelo local. Da mesma forma, tudo que intervêm no âmbito visual ou auditivo onde ocorre a cena, será incluído no texto espetacular ${ }^{20}$, multiplicando os processos de produção de signos e 
oferecendo materiais para a composição da experiência cênica.

Esta sobreposição dos planos é uma condição inerente da cena na cidade, daí a necessidade de que se pensar estratégias para consolidar o jogo no espaço, como forma de se buscar vínculos que permitam criar coletivamente um novo texto; um texto que seria a cidade em performance. O jogar no espaço urbano é performar a cidade através de cruzamentos do plano ficcional com o cotidiano, é propor jogos que confundam a lógica funcional como o ilógico do lúdico²1.

A rua, é um espaço dinâmico que não pode ser completamente organizado em função da encenação. Este espaço vivo será ao mesmo tempo espaço cênico, personagem e dramaturgia do espetáculo. De modo semelhante os e as transeuntes serão simultaneamente público e personagens, dado que a cidade é uma dramaturgia escrita e lida no próprio instante da realização da performance teatral e social (Carreira, 2019).

\section{Teatro de invasão e risco no espaço inóspito}

Alguns exemplos de encenações que nos permitem visualizar práticas que refirmam a ideia de um teatro de invasão são: BR3 do Teatro da Vertigem de São Paulo; Das saborosas aventuras de Dom Quixote e seu fiel escudeiro Sancho Pança: um capítulo que poderia ter sido e Makunaína na Terra de Pindorama, ambos do grupo goiano Teatro que Roda; Jogos de Guerra do Erro Grupo de Florianópolis; Barafonda da Cia. São Jorge de Variedades de São Paulo; Final da

20 A produção de teatralidades neste caso é intensificada e multiplicada pelas dinâmicas que caracterizam o espaço urbano. Pode-se ver o que está dentro e fora da cena de modo simultâneo. Um outro elemento fundamental para compreender os processos de produção de teatralidade se refere a que todo mundo que circula pelo âmbito no qual se realiza a apresentação, participa direta ou indiretamente de alguma camada ficcional. As pessoas podem ou não estar conscientes de que isso ocorre, mas mesmo sem saber, quando estamos ali seremos parte da cena; seremos elemento dramatúrgico, cenográfico, ou inclusive atrizes e atores.

21 Como digo no meu livro Teatro de Invasão: a cidade como dramaturgia "A cidade é um lugar que construímos a partir da nossa circulação, dos nossos hábitos, e também das imagens produzidas pelas forças das instituições e da mídia. Habitar é definir lugares, é construir zonas relacionais, é estabelecer territórios culturais. Fazer teatro na rua é uma atividade que deve ser compreendida como prática construtiva da cidade. Por isso, é interessante pensar essa arte muito além da fronteira de uma prática artística que tem como centro a busca de um suposto contato com um público que não vai ao teatro, como várias vezes se diz no ambiente do teatro de rua". (Carreira, 2019, p. 15). 
Tarde do Teatro de Caretas de Fortaleza; Página 469 do Grupo Engasga Gato de Ribeirão Preto (SP); Onde? Ação N. 2 do Oi Nóis Aqui Traveiz de Porto Alegre.

Também poderíamos nos referir a experiências de dança contemporânea que exploram tanto o espaço físico, como as formas de deslocamento dos transeuntes, e especialmente o funcionamento de sinais de trânsito e o mobiliário urbano. Entre muitas outras pode-se mencionar: Eu tenho autorização da Polícia para ficar nu aqui de Ricardo Marinelli (PR), Ronda de Zilá Muniz (SC), ou Zona de O Coletivo (SP).

Encontramos também neste âmbito da cena que invade o espaço urbano, Inúmeras performances, bem como práticas da cultura que se realizam como invasão e ruptura dos fluxos da cidade. Neste sentido, é fácil identificar os flash mobs como um modo de operação autônomo que já influenciou várias montagens cênicas, e repercute modos expressivos da performance, hoje em dia muito explorado através das mídias digitais. Um exemplo com várias apresentações nos circuitos internacionais de festivais é Utopolis da companhia Rimini Protokol.

As esculturas vivas e as artes circenses nos semáforos também são invasões, que apesar de serem de baixo impacto, produzem reações de setores conservadores. Este tem sido o caso de cidades do Sul do país que perseguem os artistas de semáforos através de normativas municipais que tratam de proibir estes tipos de manifestações artísticas considerando-as atos de vagabundagem.

Esta breve lista de exemplos merece ser ampliada, no entanto menciono estes trabalhos e práticas como referências básicas para a discussão dos procedimentos de invasão. Há de comum entre estas experiências, abordagens de espaços que não estão precedidas por uma acabada concepção de encenação construída sob as exigências de um texto dramatúrgico. O funcionamento e potencialidade dos espaços, bem como sua adversidade, são elementos fundamentais da composição destes trabalhos e práticas. Também é possível dizer que tais criações contemplam, ainda que a partir de diferentes formas, o olhar transversal dos e das transeuntes, que vêm a cena e quem vê a cena ${ }^{22}$. 
Considerando os mais diversos matizes do ato de invadir cenicamente o espaço da cidade ${ }^{23}$, pode-se pensar a invasão como projeto estético e político ${ }^{24}$ que combina a ocupação do espaço inóspito e a busca da participação dos e das transeuntes no acontecimento teatral como uma heterotopia ${ }^{25}$ (para usar um termo de Foucault), que modifica e enfrenta as regras e comportamentos hostis ao convívio.

A condição inóspita e conflitiva das ruas também contribui para que a atuação se realize com uma intensidade que pode atravessar as personagens estáveis, tirando-as dos lugares fixos na trama dramatúrgica do texto de referência. Isso pode ser constatado pelo fato de que quem atua nestas condições deverá ter uma escuta muito particular dos acontecimentos no ambiente ${ }^{26}$. Um dos elementos que devem ser considerados quando se fala de um teatro de invasão, é que o trabalho de atores e atrizes necessariamente se projeta para além da representação de personagens devido a que a energia que rompe com o funcionamento regular da cidade, é também a que influencia a cena que já não pode descansar no padrão da representação da narrativa.

Ainda que a escuta seja algo fundamental para qualquer pessoa que atua,

22 O espetáculo BR-3 por sua localização é o que menos dialoga com esse olhar, ainda que os veículos que transitavam pelas vias marginais podiam observar alguns elementos visuais e sonoros do acontecimento artístico.

23 Não excluo totalmente deste amplo espectro do gesto invasivo o teatro de rua em suas modalidades mais tradicionais, ainda que a invasão não faça parte da plataforma poética de tais formatos. A invasão que ocorre nestes casos seria de baixo impacto porque não explora formas cênicas claramente comprometidas com a desorganização dos fluxo, mas algo de desordem produz. Mesmo assim aqueles grupos e artistas que utilizam o procedimento da roda, e privilegiam as referências das formas da cultura popular, não deixam de ser intrusos/as que vão para as ruas para conquistar um lugar em um espaço inóspito que não está sempre aberto às falas teatrais.

24 Um outro aspecto que se refere à potência política do teatro na cidade diz respeito à sua capacidade de colocar em discussão - através de sua prática - as formas de vinculação social. Em uma sociedade que afirma constantemente o valor do vínculos duradouros (família e instituições) e desconfia daqueles que são fugazes e circunstanciais, o teatro na cidade, como uma fala marginal ou alterna, reconhece a fragmentação dos espaços da cidade e a fugacidade dos vínculos.

25 La heterotopía tiene el poder de yuxtaponer en un solo lugar real múltiples espacios, múltiples emplazamientos que son en sí mismos incompatibles. Es así que el teatro hace suceder sobre el rectángulo del escenario toda una serie de lugares que son extraños los unos a los otros; (en forma de emplazamientos contradictorios). (Foucault, 1967, s/p).

26 Lógico que é necessário pensar tal acontecimento dentro de um quadro da cena expandida, de modo a incorporar uma noção teatral que não se sustenta apenas - ou principalmente - no ato da representação baseada na interpretação de um texto dramático. 
nas condições deste espaço do conflito, esta escuta é importante tanto do ponto de vista da segurança, como do desenvolvimento dos jogos relacionais que se estabelecem na cena invasiva. A transformação dos usos do espaço implica que o escutar é aqui ferramenta, não da improvisação que busca conservar o fluxo do texto dramático - como é usual nos tradicionais espetáculos de rua -, mas das operações de significação que a cena vai construindo. A escuta permite construir vínculos como o acontecimento e, desta forma, elaborar em tempo real a dramaturgia da cidade. Portanto, isso se relaciona com o ler a cidade - as pessoas e suas dinâmicas - ao mesmo tempo no qual se reescreve este texto como ficção e realidade.

Quando o espaço inóspito da cidade é interferido pela performance teatral, se produz uma atuação liminar cuja intensidade da experiência decorre das tensões produzidas pelos conflitos latentes da rua, bem como pelas tensões entre o plano da realidade e o da ficção. Esta intensidade é um elemento fulcral, pois estimula que as pessoas que transitam e/ou assistem ao trabalho possam viver deslocamentos de seu cotidiano. Este é o elemento vinculante do jogo que pode transformar o fluxo, não apenas do ponto de vista da movimentação, mas especialmente no que se refere à atenção e percepção do espaço imediato. A partir disso se pode considerar a possibilidade de uma transformação das pessoas e das suas formas de perceber - pensar - imaginar a cidade.

Os momentos nos quais as pessoas aceitam cruzar a fronteira entre o cotidiano e a ficção se produzem deslocamentos da percepção de violência, e reposicionamentos com relação às práticas de controle do espaço. Isto decorre da força transformadora do jogo, e ainda que ocorra de forma efêmera, é um acontecimento de forte impacto como experiência pessoal porque implica em romper regras bem estabelecidas, e abrir fissuras no imaginário social.

Estimular uma radicalidade de jogo que, eventualmente, tenha impacto no próprio andamento da cena é assumir o fato de que o teatro que realmente invade a cidade será também invadido pela cidade. Esse jogo teria potencial para transformar pessoas que andam pela cidade em performers efêmeros do acontecimento teatral. Apesar dos riscos de se dar um salto do uso cotidiano para 
o uso poético, isso ocorre de muitas formas inesperadas. Quando se invade a cidade, e a cena não se restringe ao ato de se bem contar uma história, mas busca produzir intensidades de jogo que estimulam fluir a cidade através da fiç̧ão. Isto é, se estimula que as pessoas escrevam uma outra cidade, ainda que por um intervalo reduzido de tempo.

Apesar de que é muito difícil especificar procedimentos cênicos que garantam que isso ocorra na encenação, de modo a produzir intensidades transformadoras, é fundamental considerar esta meta como prioritária quando se pretende trabalhar a partir de uma perspectiva invasiva ${ }^{27}$. O reconhecimento deste espaço inóspito e de suas tensões é o primeiro elemento a ser considerado na busca de procedimentos de invasão. Ao duvidarmos das possibilidades de um teatro cujo eixo é a mera representação, estaremos descobrindo formas de diálogo com a cidade como organismo em permanente construção.

Propor modos de habitar o espaço urbano que escapam ao tradicional e normatizado, é enfatizar a ideia de que performar a cidade é vivê-la como espaço praticado ${ }^{28}$, é se arriscar enfrentando uma zona de violência. Michel de Certeau contrapõe o projeto ao uso, e percebe a potência transformadora do habitar dizendo que:

Así, las maneras de practicar el espacio escapan a la planificación urbanística: capaz de crear una composición de lugar, de plenos y de huecos, que permitan o que impidan las circulaciones, el urbanista es incapaz de articular esta racionalidad en hormigón sobre los sistemas culturales, múltiples y fluidos, que organizan la habitación efectiva de los espacios internos (departamentos, escaleras, etc.) o externos (calles, plazas, etc.) y que los inervan de itinerarios innumerables. Piensa y fabrica una ciudad viva; se retira cuando sobrevienen los habitantes, como delante de los salvajes que turbarán los planos elaborados sin ellos.

27 Podemos tomar como referência que a ideia de que a participação possibilita uma transformação ao incorpora o ser ficção discute as regras do controle do cotidiano. Ainda de um modo muito específico e limitado, isso apresenta semelhanças com comportamentos que irrompem nos momentos de rebelião ou explosão social, quando pessoas comuns se transformam radicalmente assumindo papeis nunca imaginados. Neste sentido, caberia refletir sobre como a ficção, ou seja, jogar representando papeis em acontecimentos teatrais também é uma maneira de colocar em crise a cultura do controle e da violência silenciosa que permeia nossas ruas.

28 De Certeau considera que o espaço existe quando é apropriado, isto é, quando praticado: "O espaço estaria em relação ao lugar da mesma forma que a palavra quando é pronunciada... Em suma, o espaço é um lugar praticado" (1994: 67). O conceito de lugar praticado pensa a cidade como espaço ser apropriado por quem a usa as ruas, habitando-a de diferentes maneiras, criando textos e articulando significados. (Certeau, 1994, p. 112) 
(Certeau, 1999, p. 189).

Não cabe nenhuma dúvida que atuar ficcionalmente implica em risco, em exposição e até em falta de controle. Isso caracteriza a atividade de atrizes e atores, e exatamente por isso, assusta os poderes mais reacionários. A teatralidade ${ }^{29}$ que interessa na cena na cidade é resultado da convivência, do conflito e da sobreposição de olhares, que não respondem a um ordenamento característico de uma perspectiva teatral representacional. As dinâmicas conflitivas são um obstáculo a que se adote tal perspectiva com comodidade. A tendência é que o fenômeno da cena na cidade se construa através de contradições que aprofundam a condição de risco da atuação. Neste caso, o trabalho com a ficção em uma situação adversa implica um colocar-se em um lugar limítrofe para estabelecer diálogos com a cidade como organismo vivo.

A condição inóspita do espaço intensifica o fato de que as ações que ocorrem ao redor da cena dialogam em tensão com a produção de linguagem. Não há tempo de pausa que permita atores e atrizes se submergirem no plano da ficção de forma absoluta, porque neste espaço se atua em contato com todas as camadas do acontecimento social.

\section{Breve conclusão com algumas provocações}

O teatro de invasão representa, ainda que de forma pontual um modo de dissidência que enfrenta a violência e o inóspito do espaço, não a partir de uma perspectiva pacificadora, mas sim do reconhecimento do conflito. Assumindo um lugar politicamente comprometido no embate contra procedimentos e comportamentos que pretendem garantir que as ruas sejam exclusivamente espaços funcionais a serviço da ordem e do consumo, a cena invasiva questiona o imaginário hegemônico, e disputa as maneiras de se pensar e fazer a cidade.

29 Utilizo aqui a noção de teatralidade proposta por Josette Féral (2015, p. 107-108) no seu livro Além dos limites - teoria e prática do teatro, ao dizer que a teatralidade é "acima de tudo, resultado de uma dinâmica perceptiva do olhar que une algo que é olhado (sujeito ou objeto) e aquele que olha”. 
Imaginar a cidade, seus espaços e suas pessoas, como lugar ideal para a experiência teatral, é dialogar com uma fantasia muito distante da realidade. Se há um elemento concreto no que se refere à cidade, é que se trata do âmbito onde a política - nos seus mais amplos sentidos - se realiza; onde os conflitos se explicitam e finalmente se resolvem no plano da história. Esse é o ponto de partida do projeto do teatro de invasão, ainda quando essa invasão não esteja estética e discursivamente articulada como prática rebelde.

Ao invadir o espaço inóspito o teatro estará enfrentando forças contrárias, tensões que o conflito inerente ao espaço político supõe. Este teatro que escolhe não estar no espaço mais protegido do palco, descobre e inventa modos de interação com uma ampla diversidade de interesses e referentes culturais. Enquanto no interior da sala teatral, quase sempre encontramos pessoas que estão próximas ao nosso universo simbólico, ou como se costuma dizer em tempos das redes sociais da internet, nas nossas bolhas, nas ruas o quadro é completamente distinto. O diverso e portanto, o conflitivo, predomina. Isso desafia os e as criadoras que desejam ir às ruas com seus trabalhos não apenas do ponto de vista das linguagens cênicas, mas também do imaginário com o qual se pensa a cidade.

A ficção realizada na rua pode ser instrumento de discussão da realidade não apenas a partir dos conteúdos da dramaturgia, mas principalmente através dos procedimentos de jogo que sobrepõem os planos da realidade a da ficção. Este teatro pode discutir a própria cidade, questionando as ficções que fabricam a ordem deste espaço. Assim, a cena invasiva sempre está perguntando: quem constrói essa ficção, com que objetivo e a partir de que referências?

Invadir a cena do cotidiano com o teatro supõe a tentativa de inversão da lógica funcional e a reivindicação do direito ao jogo. A invenção de novos usos para o espaço da rua é uma forma de romper com as regras hegemônicas que dominam este espaço privilegiando sua funcionalidade econômica. Reinventar a cidade a partir do teatro, ainda que seja uma ação política marginal, dialoga com outras muitas iniciativas que pretendem colocar no centro de nossa atividade política, habitar nossa cidade como prática transformadora. 
Romper com o ordenamento que nos exige todo o tempo operar de forma produtiva, e abrir tempos de inutilidade na cidade, é um modo de instalar o espirito da festa ${ }^{30}$ como procedimento dissidente. O teatro pode ser uma voz que reivindica sua inutilidade e reforça o prazer de jogar como razão social e política que o justifica como linguagem que interfere nas regras de controle da cidade contrapondo-se aos projetos da funcionalidade e das ruas sem conflitos, a serviço de uma cidadania leve e feliz.

\section{Referências}

BENJAMIN, Walter. Le Flâneur Éveillé, L’art de la Ville. In Exposição WALTER BENJAMIN Le passant, la trace (catálogo), Centre Georges Pompidou, Galerie Nord, Paris 23 février - 23 mai 1994. Citado por Jorge Mario Jauregui. Disponível em: http://www.jauregui.arq.br. Acesso em: 03 fev. 2020.

CANCLINI, Nestor García. Imaginarios Urbanos. Buenos Aires: EUDEBA, 2005.

CARDASO, Pedro Luis Lorenzo. Principales teorías sobre el conflict social. In Norba - Revista de Historia. Cáceres, v.15, 2001. Disponível em:

https://dialnet.unirioja.es/descarga/articulo/241031.pdf. Acesso em: 03 mar. 2020.

CARREIRA, André. Sobre um ator para um teatro que invade a cidade. In: Moringa, João Pessoa, Vol. 2, n. 2, jul./dez. de 2011.

CARREIRA, André. Entrevista. In Jornal Caixa de Ponto. Florianópolis, n.1, 2015, Disponível em: https://7def63e5-712c-41aa-b56cd66c7d4ff3e2.filesusr.com/ugd/23361d 841642b3a38a465a9b79f6946fa010cf.pdf. Acesso em: 07 fev. 2020.

CARREIRA, André. Teatro de invasão: a cidade como dramaturgia. São Paulo: HUCITEC, 2019.

CASTEL, Robert. ¿La inseguridad social: qué es estar protegido? Buenos Aires: Manantial, 2008.

COSTA, Márcia Regina da. A violência urbana é particularidade da sociedade brasileira?. In: São Paulo em Perspectiva, São Paulo, vol.13, no.4,1999.

COSTA, Pedro e LOPES, Ricardo. Dos dois lados do espelho: diálogos com um

${ }^{30}$ Sobre a noção de festa ver Roberto Da Matta, 1997. 
bairro cultural através da intervenção urbana. In: Etnográfica Revista do Centro em Rede de Investigação em Antropologia. vol. 22, n. 2, 2018. Disponível em: https://journals.openedition.org/etnografica/5572. Acesso em: 07 mar. 2020.

DA MATTA, Roberto. A casa \& a rua espaço, cidadania, mulher e morte no Brasil. Rio de Janeiro: Editora Rocco, 1997.

CERTEAU, Michel de. A invenção do cotidiano. Petrópolis: Vozes, 1994.

CERTEAU, Michel de. La cultura en plural. Buenos Aires: Ed. Nueva Visión. 1999.

DELGADO, Manuel. Espacio público como ideología. Madrid: Libros de la Catarata, 2011.

DELGADO, Manuel. El idealismo del espacio público. Revista Papeles de relaciones ecosociales y cambio global. Barcelona, n. 111, 2010.

DURKHEIM, Emile. Suicidido: estudo de sociologia. São Paulo: Martins Fontes, 2000.

DUVIGNAUD, Jean. El juego del juego. México: Fondo de Cultura Económica, 1980.

FÉRAL, Josette. Além dos limites - teoria e prática do teatro. São Paulo: Ed. Perspectiva, 2015.

FOUCAULT, Michel. De los espacios otros (1967). In Fotocopioteca. N.43, 2014. Disponível em:

http://www.lugaradudas.org/archivo/publicaciones/fotocopioteca/43 espacios ot ros.pdf. Acesso em: 20 abr. 2020.

FURLAN Reinaldo e SILVA Mauricio. Corpo, utopia e limite no pensamento de Michel Foucault. In: Fractal, Revista de Psicologia. vol.31 no.2 , 2019. Disponível em: https://www.scielo.br/scielo.php?script=sci abstract\&pid=S198402922019000200111\&lng=en\&nrm=iso\&tlng=pt. Acesso em 03/01/2020.

GARCÍA CANCLINI, Nestor. Imaginarios urbanos. Buenos Aires: EUDEBA, 2005.

JAVIER, Francisco. La renovación de la escena argentina está alojada en las pequeñas salas. In: Cuadernos de Picadero/INET, Buenos Aires, n. 4, Diciembre, 2004.

LYNCH, Kevin. A imagem da cidade. São Paulo: Martins Fontes, 2006.

SCHECHNER, Richard. Environmental Theater. New York: Applause, 1994. 
SLAVOJ, Zizek. Violencia: seis reflexiones marginales. Barcelona: Paidós, 2009.

STRAEHLE, Edgar. En torno a la violencia burocrática: Observaciones acerca de uno de los rostros de la violencia contemporánea. In: Anuari del Conflicte Social. 2014. Disponível em: https://revistes.ub.edu/index.php/ACS/article/view/12292. Acesso em: 10 abr. 2020.

WISNIK TEIXEIRA, Guilherme. Dentro do labirinto: Hélio Oiticica e o desafio do "público" no Brasil. In: Revista ARS, São Paulo, v. 15 n. 30, 2017.

Recebido em: 08/06/2020

Aprovado em: 25/07/2020 